\title{
A global reconnaissance of particulates and metals/ metalloids in untreated drinking water sources
}

\author{
Jonathan W. Peterson (D) Benjamin M. Fry • Daniel R. Wade • Ford J. Fishman • Jacob T. Stid • \\ Jonas M. Peterson - Cleveland E. Tarp - Randall D. Wade · Sarah A. Brokus • Michael J. Pikaart • \\ Brent P. Krueger $\cdot$ Aaron A. Best
}

Received: 5 June 2020 / Accepted: 15 April 2021 / Published online: 28 April 2021

(C) The Author(s) 2021

\begin{abstract}
Metal and metalloid contamination in drinking water sources is a global concern, particularly in developing countries. This study used hollow membrane water filters and metal-capturing polyurethane foams to sample 71 drinking water sources in 22 different countries. Field sampling was performed with sampling kits prepared in the lab at Hope College in Holland, MI, USA. Filters and foams were sent back to the lab after sampling, and subsequent analysis of flushates and rinsates allowed the estimation of suspended solids and metal and other analayte concentrations in source waters. Estimated particulate concentrations were 0-92 mg/L, and consisted of quartz, feldspar, and clay, with some samples containing metal oxides or sulfide phases. As and $\mathrm{Cu}$ were the only analytes which occurred above the World Health Organization (WHO) guidelines of $10 \mu \mathrm{g} / \mathrm{L}$ and $2000 \mu \mathrm{g} / \mathrm{L}$, respectively, with As exceeding the guideline in $45 \%$ of the sources and $\mathrm{Cu}$ in $3 \%$. Except for one value of $285 \mu \mathrm{g} / \mathrm{L}$, As concentrations were 45-200 $\mu \mathrm{g} / \mathrm{L}$ (river), 65-179 $\mu \mathrm{g} / \mathrm{L}$ (well),
\end{abstract}

J. W. Peterson $(\bowtie) \cdot$ D. R. Wade · J. T. Stid · C. E. Tarp Department of Geological \& Environmental Sciences, Hope College, Holland, MI, USA

e-mail: peterson@hope.edu

B. M. Fry · J. M. Peterson · M. J. Pikaart · B. P. Krueger Department of Chemistry, Hope College, Holland, MI, USA

F. J. Fishman - R. D. Wade · S. A. Brokus · A. A. Best Department of Biology, Hope College, Holland, MI, USA and $112-178 \mu \mathrm{g} / \mathrm{L}$ (tap). Other metals (Ce, Fe, Mg, $\mathrm{Mn}, \mathrm{Zn}$ ) with no WHO guideline were also detected, with $\mathrm{Mn}$ the most common. This study demonstrated that filters and foams can be used for reconnaissance characterization of untreated drinking water. However, estimated metal and other analyte concentrations could only be reported as minimum values due to potential incomplete retrieval of foam-bound analytes. A qualitative reporting methodology was used to report analytes as "present" if the concentration was below the WHOguideline, and "present-recommend retesting" if the concentration was quantifiable and above the WHO guideline.

Keywords Global water reconnaissance $\cdot$ Metal/ metalloid contamination - Point-of-use water filters . Untreated-drinking water

\section{Introduction}

Contamination of drinking water sources with dissolved metals is a growing global concern in developed countries (Chappells, 2015; Hanna-Attish et al., 2016; Harvey et al., 2016; Le Bot et al., 2016), and also particularly in the developing world where untreated sources are common (Bajwa et al., 2017; Dundar \& Altundag, 2007; Karagas et al., 2015; Mohiuddin et al., 2011; Reza \& Singh, 2010; Wyatt et al., 1998). Health effects from metal exposure are varied and comorbid, including osteomalacia from cadmium $\mathrm{Cd}$ 
(Yoshida et al., 1999); cognitive impairment from lead (Pb) (AAP, 2005); neurological, cardiovascular, and renal diseases from mercury $(\mathrm{Hg}$ ) (Mamtani et al., 2011); immunotoxicity and pulmonary toxicity from nickel (Ni) (Das et al., 2008); and alimentary cancers from chromium (Cr) (Zhitkovich, 2011), to only mention a few. Arsenic (As) is possibly the most publically known metalloid contaminant on the global scale because of its widespread detection (Chowdhury et al., 2016) and its myriad human-health effects (Mamtani et al., 2011). In addition to the well-published crisis in Bangladesh (Chakraborti et al. 2015; Smith et al., 2000), it has been estimated that a minimum of about 140 million people in 50 countries have been drinking arsenic-contaminated water at levels above the World Health Organization (WHO) guideline value of $10 \mu \mathrm{g} / \mathrm{L}$ (WHO, 2018).

In order to contribute to the understanding of the scope and characteristics of this world-wide metal contamination issue, this paper presents results from part of a global reconnaissance survey which investigated 71 untreated drinking water sources in 22 countries (Fig. 1) for the presence of dissolved metal contamination. Analytes included arsenic (As), barium $(\mathrm{Ba})$, cadmium $(\mathrm{Cd})$, cerium $(\mathrm{Ce})$, chromium $(\mathrm{Cr})$, copper $(\mathrm{Cu})$, iron $(\mathrm{Fe})$, magnesium $(\mathrm{Mg})$, manganese $(\mathrm{Mn})$, nickel $(\mathrm{Ni})$, lead $(\mathrm{Pb})$, antimony $(\mathrm{Sb})$, selenium (Se), and zinc ( $\mathrm{Zn})$. Suspended load particulate matter can be a substrate and transport vehicle for metal, metalloid, and other contaminants (Rice et al., 2002; Dundar \& Altundag, 2007; Alkhatib \& Berna, 2008; Maniquiz-Redillas et al., 2014; Djukic et al., 2016; Nasrabadi et al., 2018; Yang et al., 2018); therefore, another part of this study was to collect concentration and composition data on suspended load from the same untreated drinking water sources tested for dissolved analytes.

Although many studies have been published on metal contamination of drinking water sources (Ćavar et al., 2005; Gowd \& Govil, 2008; Mosaferi et al., 2008; Badr et al., 2011; Wongsasuluk et al., 2014; Chowdhury et al., 2016), this study was unique in several ways. First, it utilized an innovative method for testing water sources. This study eliminated the

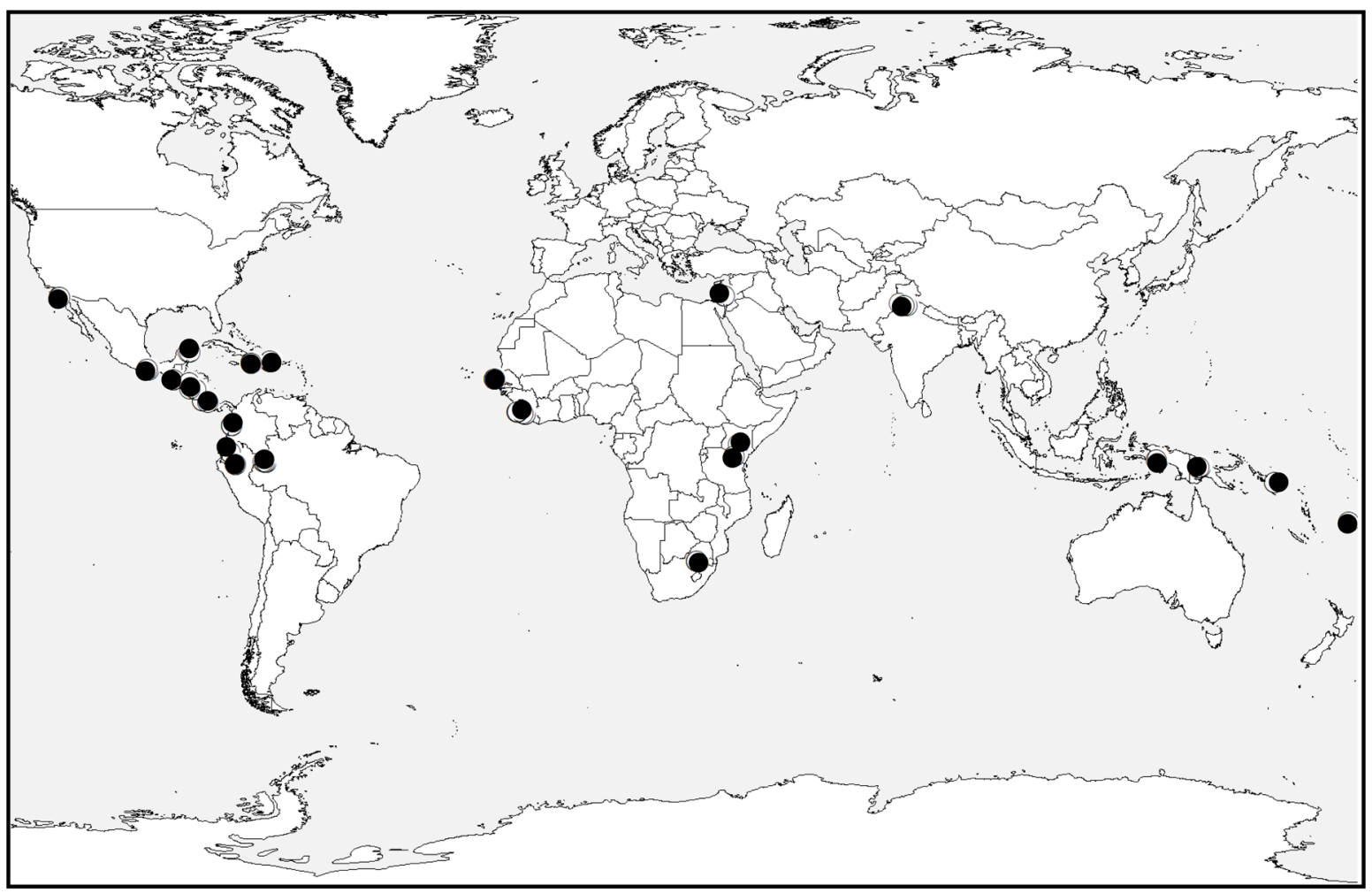

Fig. 1 Map of countries where untreated drinking water was sampled in this study 
problem of shipping water internationally by capturing the water characteristics on a filter and foam, which were comparatively much easier and less expensive to transport. Second, samples were collected by the same protocol at all 71 sources, thereby minimizing variability due to field collection. Third, this was a reconnaissance tool with the purpose of identifying hotspot sites with high inorganic contaminant levels which could be targeted for subsequent, direct analysis of the water. This approach may avoid expensive analysis on waters which pose little to no long-term human health threat.

The work reported in this paper represents a twopart contribution, the project design and the results. The design was a new approach to providing water quality data to developing country stakeholders. The subsequent deliverable was reconnaissance data which can be easily communicated to technicallyeducated or non-technically trained decision-makers.

\section{Materials and methods}

Sampling

\section{Field sampling-particulates/suspended load}

The foundation of this project was global field sampling of untreated drinking water sources performed by trained field staff and volunteers from several nongovernmental organizations (NGOs). Sampling was done with $12-\mathrm{cm} \times 3.5-\mathrm{cm}$-diameter point-of-use 0.1 $\mu \mathrm{m}$ hollow fiber membrane filters (Sawyer Products, Inc.). Field kits containing filters, detailed instructions, and accessories to perform systematic sampling were assembled at Hope College in Holland, MI, USA, and sent to 71 locations in 22 countries. Water sources sampled included rivers, holding tanks, catchments, groundwater wells, wetlands, and household taps which conveyed untreated water. Sites were mostly rural or in small villages. New 18.9-L (5 gallon) plastic buckets were fitted with filters and tubing (Fig. 2). Buckets were rinsed with source water then filled with $16 \mathrm{~L}$ of source water which was allowed to gravity drain through the filter. After the bucket was drained, the filter was detached and four $(50 \mathrm{~mL})$ volumes of air were pushed through the sample with a syringe to flush out residual water. Four samples were collected in this manner at

\section{Field Bucket}
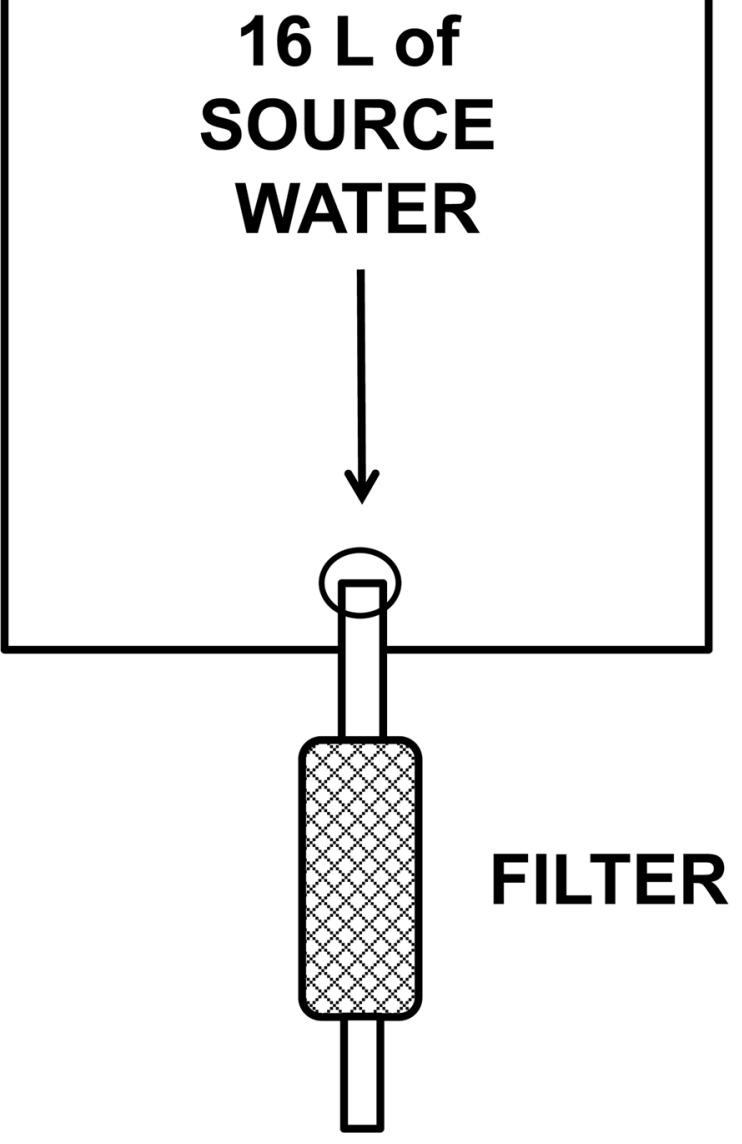

Fig. 2 Schematic of bucket and filter sample collection method as used in the field

each site. Filters were then capped at both ends, placed in a zip-sealed plastic bag, and shipped back to Hope College.

\section{Particulate retrieval}

An apparatus (Fig. 3) was designed, and a procedure was developed to backflush filters returned from the field in order to reclaim the source water particulates captured on the filter. The filter was attached to the apparatus in a reverse orientation. Two $(125 \mathrm{~mL})$ 
Fig. 3 Schematic illustrating the laboratory back-flushing procedure to retrieve the suspended load particulates sampled in the field

volumes of $18 \mathrm{M} \Omega$ resistivity reverse osmosis (RO) water were flushed through the filter with $103 \mathrm{kPa}$ air, and the flushate containing removed particulates was collected in a volumetric flask. Numerous trials with known amounts of material loaded onto filters determined that using two sequential slugs of $125 \mathrm{~mL}$ of water, at $103-\mathrm{kPa}$ air pressure, provided the highest systematic yield of filtered material $(95 \pm 5 \%)$. One of the four field samples was used to determine total suspended solids (TSS), and if that concentration was too small for particulate characterization, a composite of the other three was used to characterize the inorganic solids captured on the filters.

\section{Dissolved metal/target analyte sampling}

Drinking water sources were sampled for dissolved analytes by using metal-capturing polyurethane foam blocks (Sawyer Products, Inc.) to sequester analytes from source water samples. A standardized field protocol was employed at all sampling sites (Fig. 4). Source water was first passed by gravity flow through the $0.1-\mu \mathrm{m}$ hollow membrane filter to remove particulate matter, as described above. Three separate $(70 \mathrm{~mL})$ aliquots of filtered water were then placed in zip-sealed plastic bags along with a foam block. The foam was squished/kneaded with the water in the bag for $1 \mathrm{~min}$, after which the water was decanted. The wet foam was then squeezed to remove residual water and shipped in the sealed bag back to Hope College for analysis.

\section{Metal/target analyte retrieval}

The returned field foams were processed through an acid-wash procedure to recover trapped analytes. Foam blocks were first dried at $100{ }^{\circ} \mathrm{C}$ for $24 \mathrm{~h}$ then weighed. Blocks were cut into two pieces and placed in a desiccator. Prior to rinsing, one half-block piece was reweighed and placed in an acid-washed $50-\mathrm{mL}$ syringe equipped with a $0.45-\mu \mathrm{m}$ syringe tip filter. Thirty (30) $\mathrm{mL}$ of $3 \%$ trace-metal grade nitric acid $\left(\mathrm{TMG} \mathrm{HNO}_{3}\right)(\mathrm{pH} \sim 0.7)$ was added to the open syringe holding the foam, and the plunger was then inserted. After $5 \mathrm{~min}$ of foam-acid contact,

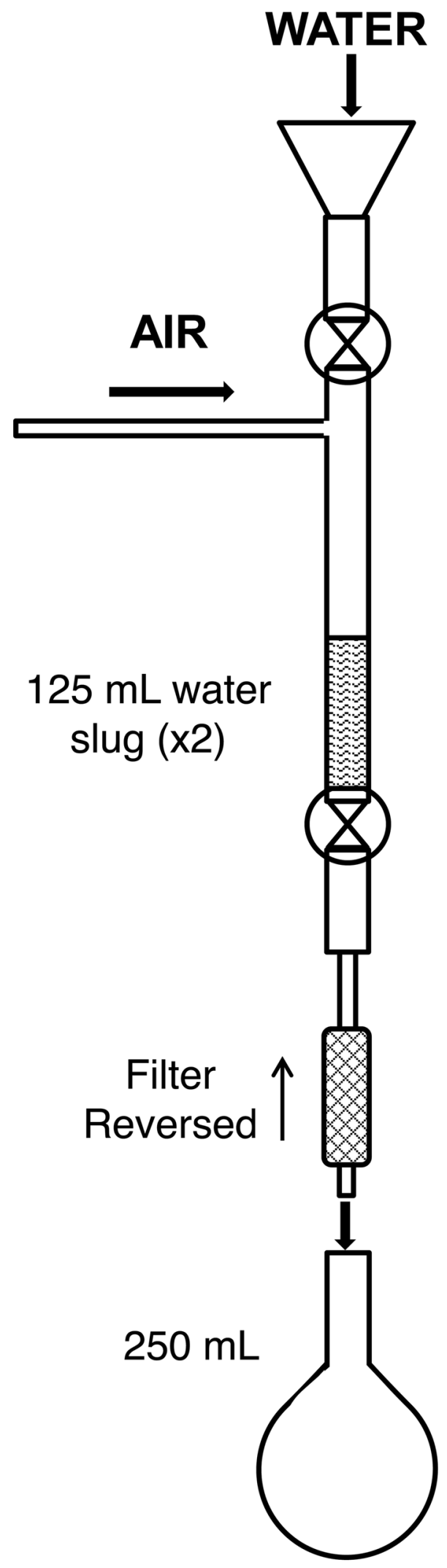


Fig. 4 Schematic illustrating the field sample collection process utilizing polyurethane foam blocks (black rectangles) for the capture of dissolved analytes

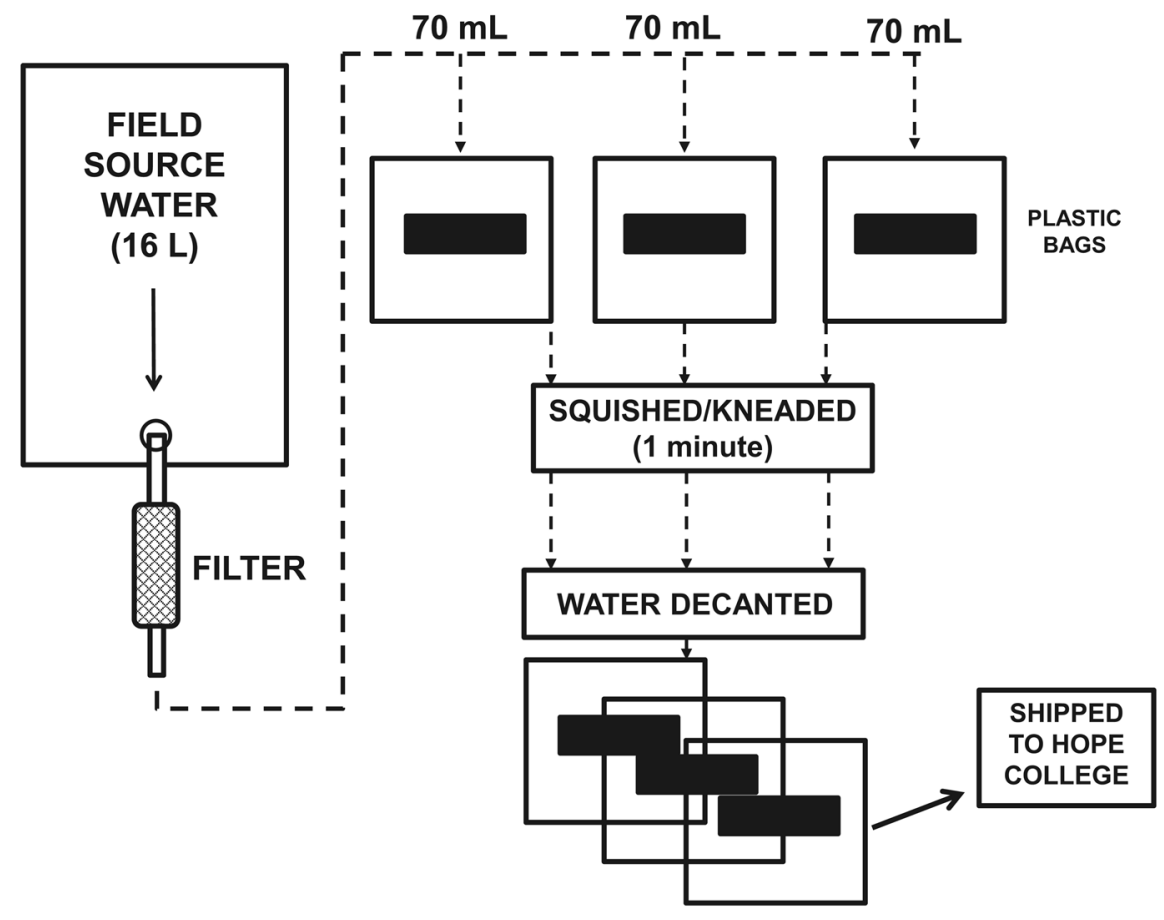

immediately for analysis. Attenuation (transmittance and absorbance) and scattering were measured at multiple wavelengths between 360 and $880 \mathrm{~nm}$ for 20 replicates. Relative error on attenuation measurements was $<1 \%$. Samples were agitated vigorously between each replicate measurement.

TSS concentration was estimated by comparison to standard curves of known suspended load (Fig. 5). Standard attenuation equations were developed for individual common rock-forming minerals which were considered representative of major types of geologic terrains, based on the assumption that the suspended load in any location is systematically reflective of the eroding substrate (Blake \& Peters, 2015; Garzanti et al., 2011; Meybeck et al., 2003; Nasrabadi et al., 2018). All source sites were categorized as one of the following: plutonic, volcanic, metamorphic, or sedimentary. The representative minerals used were albite+labradorite (plutonic), labradorite + montmorillonite (volcanic), albite + montmorillonite (metamorphic), and quartz+kaolinite (sedimentary). Many of these minerals were identified in the particulate material recovered upon back-flushing. To be noted, "concentration" is a commonly used unit in this type of study, though samples are not solutions, sensu stricto, 
Fig. 5 Standard curves of light attenuation versus TSS for model particulate suspensions. Correlation coefficients $\left(\mathrm{R}^{2}\right)$ were $>.99$ for all curves except for calcite, which was .98

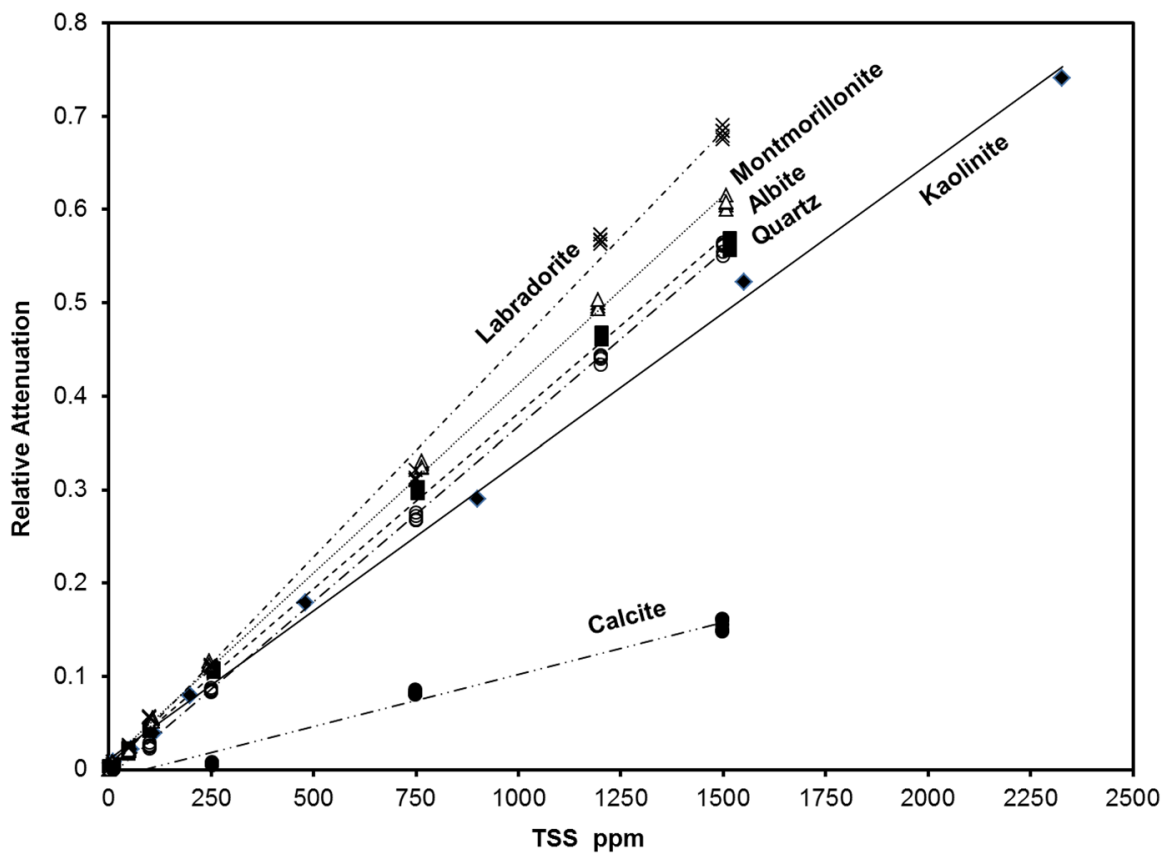

but rather suspensions. Mineralogy was determined and/ or estimated by powder X-ray diffraction (PXRD) techniques $\left(\right.$ Rigaku ${ }^{\circledR}$ MiniFlex + ) and SEM-EDS (Hitachi ${ }^{\circledR}$ TM-3000) analysis.

\section{Metals/Analytes in rinsates (dissolved elements)}

Rinsates were analyzed by ICP-OES techniques with a PerkinElmer® Avio 200 instrument. Analytes and detection wavelengths (nm) were As (193.69), Se (196.026), $\mathrm{Zn}$ (206.200), Pb (220.353), Cd (228.802), Ni (231.604), $\mathrm{Fe}$ (238.204), Mn (257.610), Cr (267.716), Mg (279.077), Cu (327.393), Ce (413.764), Sb (206.836), Ba (233.527), $\mathrm{Se}$ (203.985), and $\mathrm{Cu}$ (324.752).

Quality assurance (QA) and quality control (QC) checks were consistent with a modified protocol (EPA Method 200.7), as summarized in Sarojam (2010). Raw data were processed through a statistical comparison routine and reverse protocol algorithm to estimate target analyte concentrations in field drinking water sources (Fig. 6). Method detection limits (MDLs) and limits of quantification (LOQs) for analytes $(\mu \mathrm{g} / \mathrm{L}, \mathrm{ppb})$ in this study were (MDL/LOQ): $\mathrm{Ba}(1.3 / 13), \mathrm{Cr}(0.4 / 4), \mathrm{Mn}$ (0.6/6), Fe (8.6/86), Ni (1.2/12), Zn (3.6/36), Cd (0.8/8), Se (26.1/261), As (7/70), Sb (3.7/37), Pb (1.5/15), Cu (1.1/11), Ce (4.5/45), and $\mathrm{Mg}$ (2.6/26).
Results reported from the analyte retrieval and analysis procedures were initially predicated on the assumptions: (1) All analytes present in the 70-mL field sample were transferred/bound to the foam in the plastic bag and (2) all analytes bound to the foam were rinsed off by flushing with 3\% trace-metal grade nitric acid. If $<100 \%$ of the dissolved analytes were bound to the foam, and/or $<100 \%$ of the analytes were rinsed off the foam in the lab, then the final measured quantity was a minimum estimate of dissolved analytes in the drinking water source.

In order to test these assumptions, single-element foam retention/recovery testing was performed.

with 6 target analytes: $\mathrm{Ba}, \mathrm{Pb}, \mathrm{As}, \mathrm{Cd}, \mathrm{Cr}$, and $\mathrm{Cu}$. Aqueous solutions of 10, 20,100, 200, and $1000 \mathrm{ppb}$ of single-element analytes were mixed with foams, rinsed with acid and analyzed to mimic field and laboratory procedures. Results were compared to $0 \mathrm{ppb}$ controls. Three different solutions from each experiment were analyzed. These were the input solution, the decanted supernatant after mixing, and the rinsate after filter pressing the foam with nitric acid.

Experiments revealed that an adjustment factor (AF) needed to be applied to measured foam rinsate concentrations in order to match input water concentrations. The AF was dependent on analyte and concentration ranges, with the smallest 
Fig. 6 Processing flow chart scheme for estimating the field concentration of dissolved analytes in untreated drinking water sources based on the analysis of foam rinsates. MDL $=$ method detection limit and $L O Q=$ limit of quantification

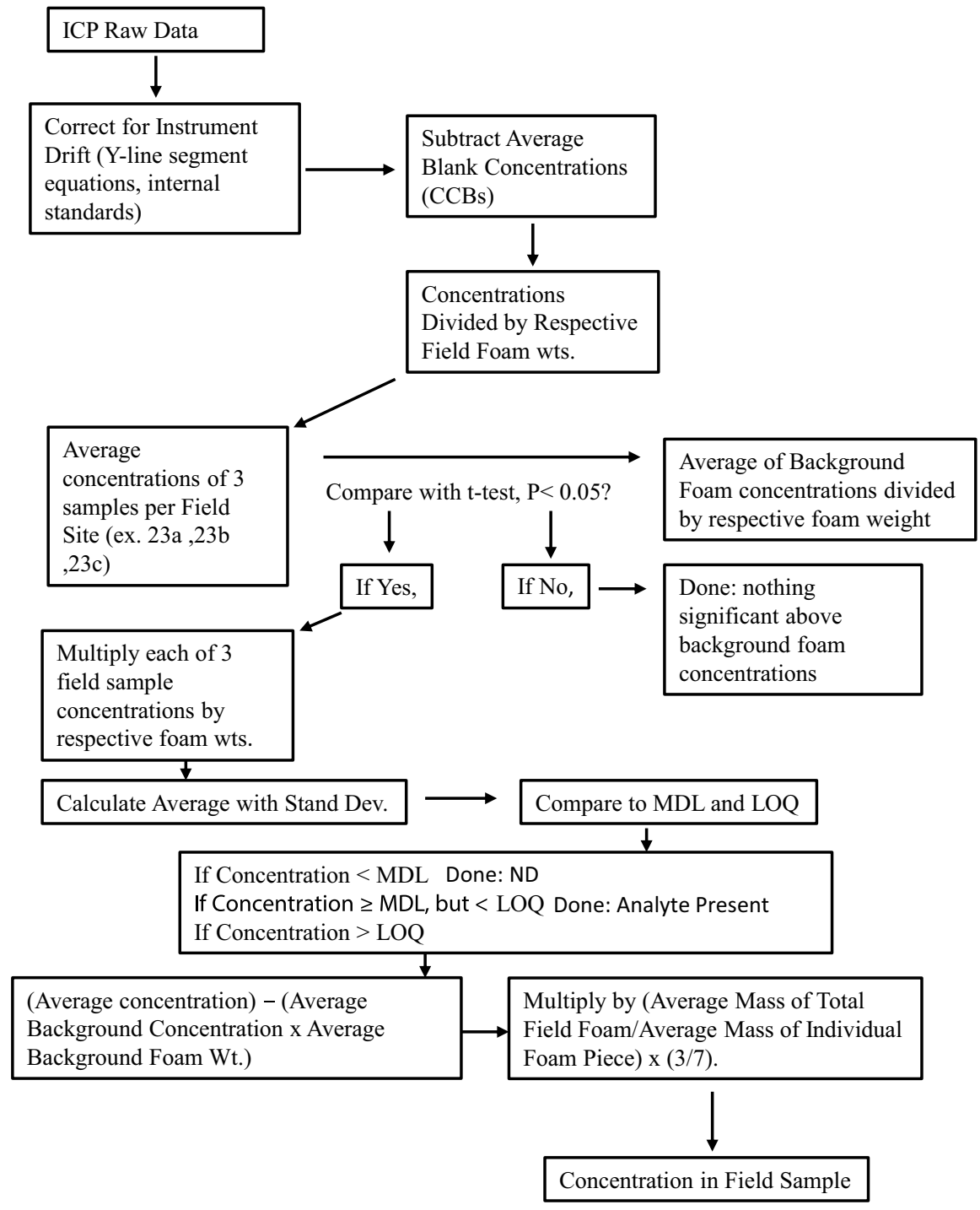

adjustments for all analytes (AF closest to 1.0) in the $10-100 \mathrm{ppb}$ water concentration range, and the largest in the 100-1000 ppb water concentration range (Table 1). These results indicate that except for $\mathrm{Ba}$, the assumptions of $100 \%$ analyte binding to the foam from source water, and $100 \%$ removal of analytes from the foam into the acid rinsate were not valid. Therefore, the target analyte concentrations
Table 1 Adjustment factors (AF) for foam rinsates based on laboratory retention tests

\begin{tabular}{|c|c|c|c|c|c|c|}
\hline \multirow[b]{2}{*}{ Analyte } & \multicolumn{6}{|c|}{ Water concentration range $(\mu \mathrm{g} / \mathrm{L})$} \\
\hline & $10-20$ & $10-100$ & $10-200$ & $20-1000$ & $100-1000$ & $200-1000$ \\
\hline As & & & $6.5( \pm 3.3)$ & & & $9.7( \pm 1.1)$ \\
\hline $\mathrm{Ba}$ & & $0.7( \pm 0.2)$ & & & & $2.3( \pm 0.1)$ \\
\hline $\mathrm{Cd}$ & & & & $3.2( \pm 0.6)$ & & \\
\hline $\mathrm{Cr}$ & $4.2( \pm 2.7)$ & & & & $12.9( \pm 2.7)$ & \\
\hline $\mathrm{Cu}$ & & & $1.8( \pm 2.0)$ & & & $3.3( \pm 0.1)$ \\
\hline
\end{tabular}


determined in this study are minimum concentration levels for the source waters sampled in the field.

As another check on foam binding, retention, and AF, field tests on local lake water (Holland, MI, USA) were performed in which direct analyses of water were compared to analyses of rinsates from lake samples subjected to the same field collection and rinsing protocols used in the global survey. An AF from foam retention tests could only be applied to the lake water tests for $\mathrm{Cu}$, because this was the only analyte detected above the LOQ. Applying the $\mathrm{AF}$ to the foam rinsates resulted in a predicted $\mathrm{Cu}$ concentration of $45 \mu \mathrm{g} / \mathrm{L}( \pm 22 \mu \mathrm{g} / \mathrm{L})$ compared to $11 \mathrm{ug} / \mathrm{L}( \pm 13 \mathrm{ug} / \mathrm{L})$ measured in the water samples directly. These values are very near the LOQ for $\mathrm{Cu}$ of $11 \mu \mathrm{g} / \mathrm{L}$. The lack of distinction between these concentrations (within 1 standard deviation) supports the AF approach and the conclusions that concentrations reported in this study should be considered minimum levels for the sources sampled.

There are some cautionary considerations regarding the laboratory foam retention tests and AF determinations. First, the tests were for single-analyte solutions, the behavior of which may not have reflected the processes active when multiple elements were present in solution with subsequent competition for adsorption sites on the foam. Also, the aqueous matrix of the test solutions (RO water) was not representative of the complex multi-constituent matrix of natural field waters.

\section{Results and discussion}

\section{Particulates-suspended solids}

Estimated particulate concentrations in the drinking water sources, as represented by TSS, are given in Table 2, along with qualitative characterization of the particulate constituents. TSS ranges from 0 to $92 \mathrm{mg} / \mathrm{L}$ (ppm), with $86 \%$ of the sources containing $<20 \mathrm{mg} / \mathrm{L}$ of suspended particulates. The percentage of particulates consisting of clays was estimated from X-ray diffractograms, and approximated to the nearest $5 \%$ by volume. Phases identified on PXRD were mostly quartz, feldspar, and clay, with a small number of samples containing metal oxides or sulfide phases. Results from SEM-EDS analysis are also shown in Table 2 as elements detected in a scan of the sample which are not directly attributable to clay, feldspar, or quartz phases, and are not other common rock forming elements ( $\mathrm{Al}, \mathrm{Si}, \mathrm{Na}, \mathrm{K}, \mathrm{Ca}, \mathrm{Mg}$ ). Even though $\mathrm{Fe}$ is a common rock-forming element, it is separated out because of its potential affinity and association with As (Aredes et al., 2012; Catalano et al., 2011).

Figure 7 is a comparison of the estimated TSS results with the various drinking water sources sampled in the study. River sources had the largest range of TSS, with the highest values approaching $100 \mathrm{mg} / \mathrm{L}$. These levels were similar to other rivers studied and would be considered relatively low TSS (Meybeck et al., 2003), with higher concentrations commensurate with faster-flowing streams with higher bed shear stresses (Alkhatib \& Berna, 2008), terranes dominated by unconsolidated geologic material (Cagnin et al., 2017), substrate disruptive anthropogenic activity (Nasrabadi et al., 2018), or a combination of these factors. Catchments in this study consisted of sequestered water within earthen basins or impoundments, a reason the ranges of TSS were similar to river concentrations. Suspended solids of groundwater wells was expected to be low because of the relatively low linear velocity of flow through an aquifer; however, values ranging over 4 orders of magnitude $10^{0}-10^{3} \mathrm{mg} / \mathrm{L}$ have been reported (Degueldre et al., 2000; McDowell-Boyer et al., 1986; Peterson et al., 2019), indicating 1-30 mg/L measured in this study was within the typical range. High levels of groundwater TSS reported could be the result of non-ideal well design or installation, and/or reflect aquifer matrices containing a significant proportion of particles which are suspendible only upon pumping or bailing (Peterson et al., 2019).

Particles were mostly composed of clays (kaolinite, illite, and montmorillonite), feldspars, and quartz. This mineralogy, along with the relative proportion of clays (Table 1), were both consistent with the suspended load mineralogy of the near surface water of the Ganga River, considered one of the largest representative models of suspended load in the world (Garzanti et al., 2011). The elemental compositions of particulate phases which could not be identified as specific minerals are also listed in Table 2. The presence of $\mathrm{Fe}, \mathrm{Ti}, \mathrm{Cu}, \mathrm{Zn}, \mathrm{Ni}, \mathrm{Cr}, \mathrm{Ba}$, 


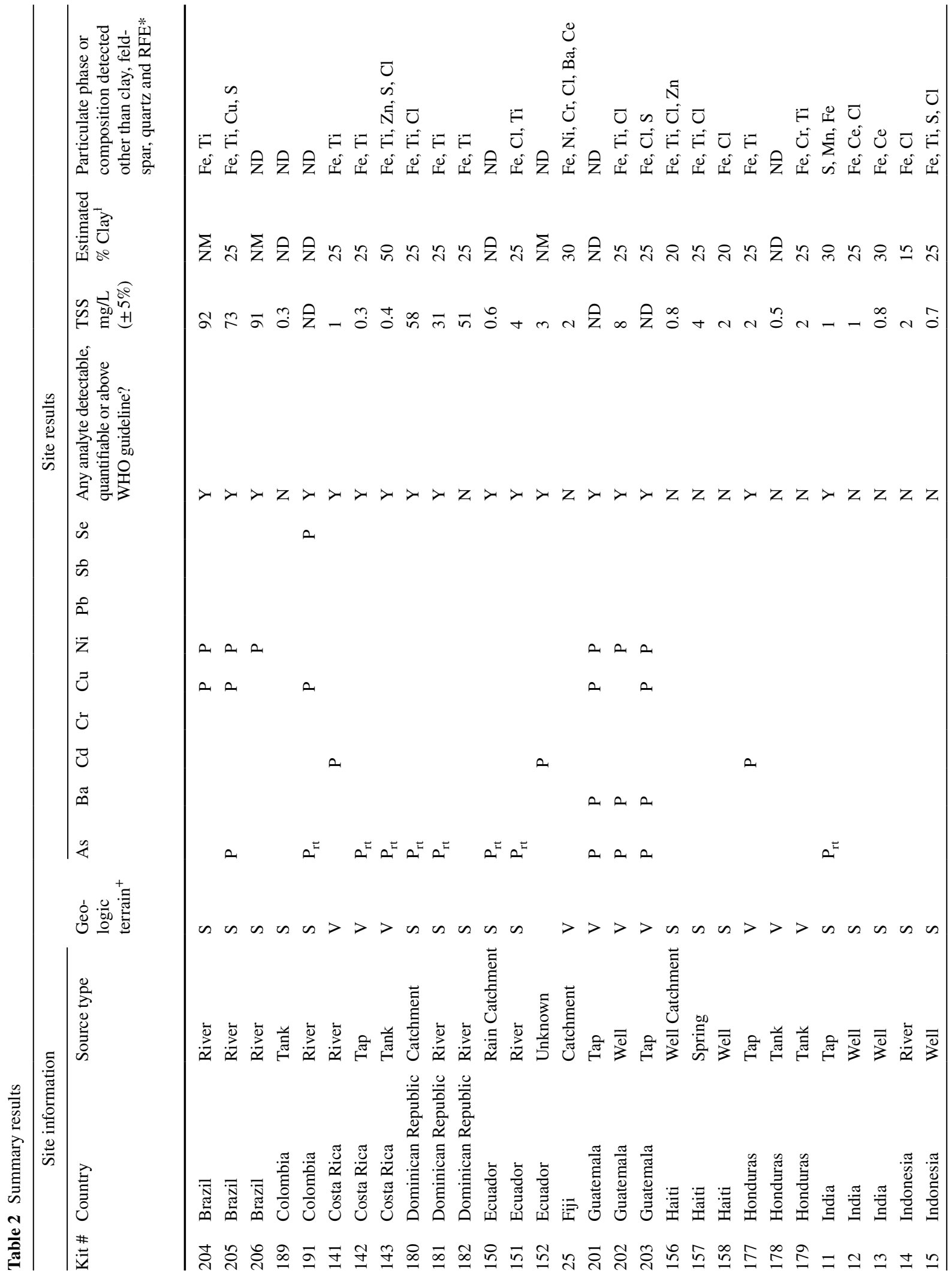




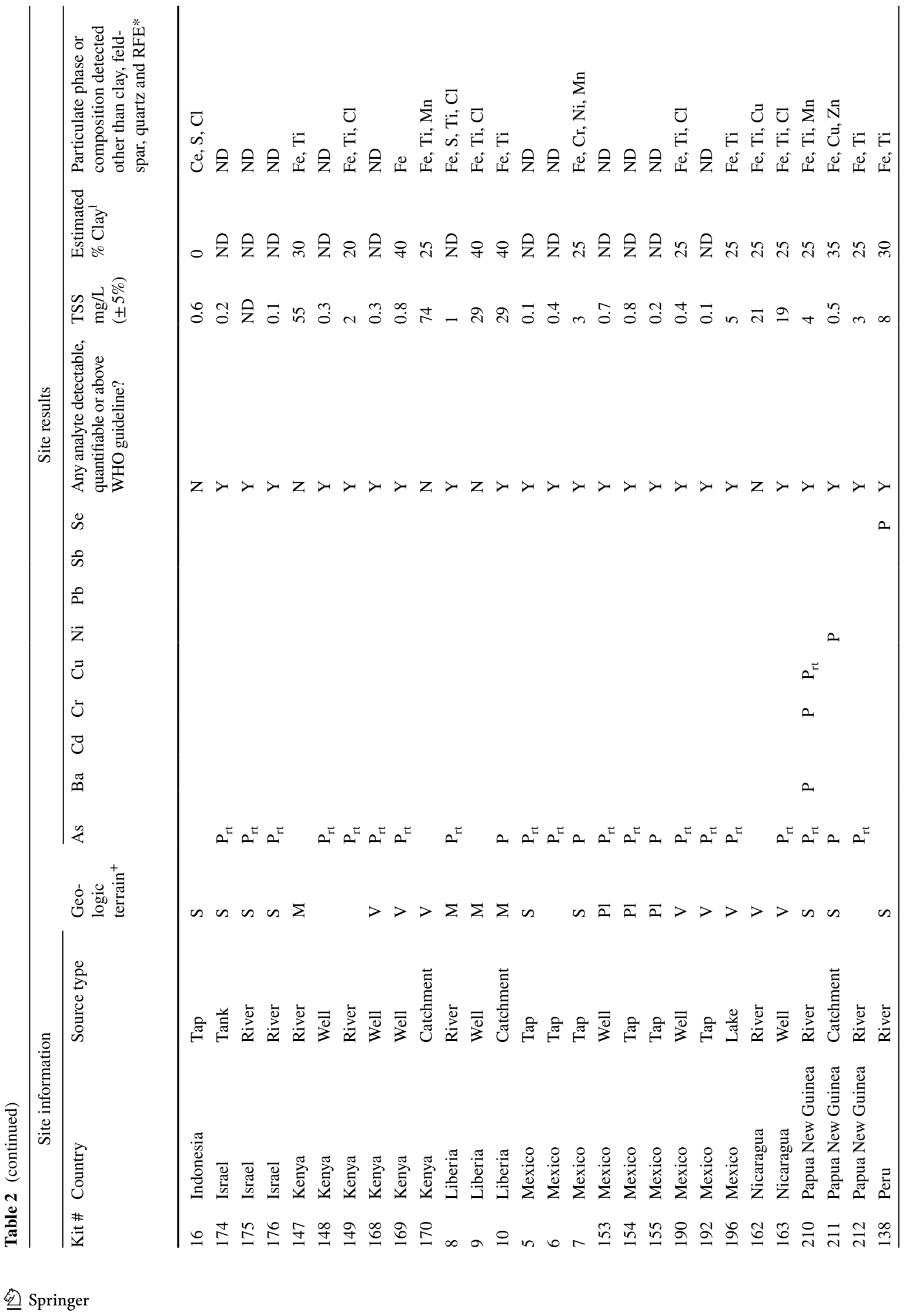




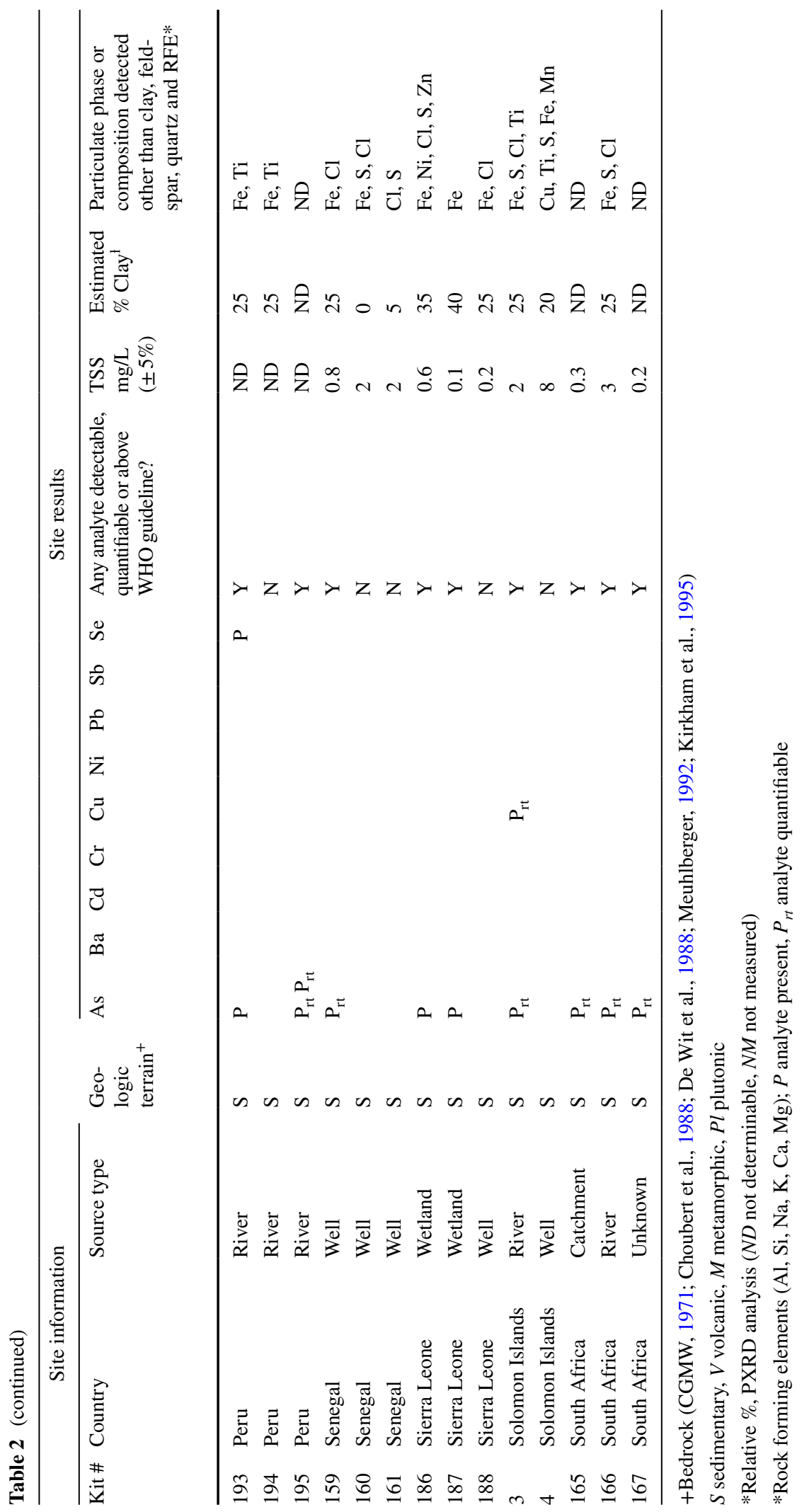


Fig. 7 TSS results for different types of untreated drinking water sources sampled in this study

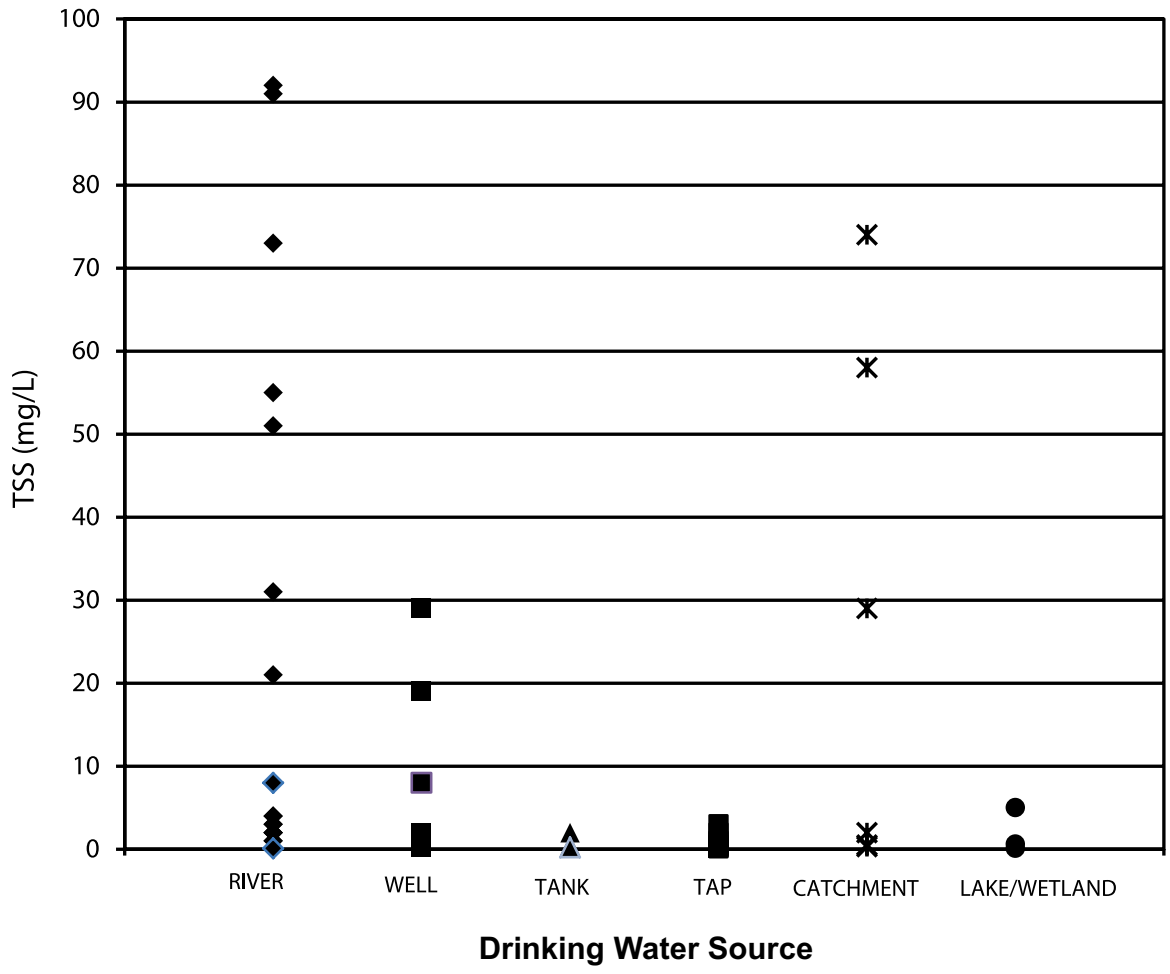

and $\mathrm{Mn}$ reflects the progressive enrichment of elements contained in, or adsorbed to, slow-settling clays or oxyhydroxides (Garzanti et al., 2011). These elements are commonly reported constituents in drinking water sources in the developing countries (Chowdhury et al., 2016). Sulfur and chloride are indicative of ore-phases of the metal or metalloid elements, and the detection of the light rare earth element (LREE) Ce suggests the presence of allanite, monazite, or other LREE-bearing minerals.
Dissolved metals and other analytes

Results were compiled into 3 categories for each analyte for every site (Fig. 8). These categories were nondeterminable/not significant (ND/NS), present $(\mathrm{P})$, and present with recommendation for re-testing $\left(\mathrm{P}_{\mathrm{rt}}\right)$. ND indicates that the analyte concentration was below the method detection limit (MDL) for the protocol and instrument used in the study. NS indicates the analyte concentration was statistically indistinguishable
Fig. 8 Categorization scheme for various target analyte concentrations determined in samples. MDL $=$ method detection limit and $\mathrm{LOQ}=$ limit of quantification. ND/ $N S=$ non-determinable/not significant; $P=$ present, but not quantifiable; $P_{r t}=$ quantifiable; $\mathrm{WHO}=$ World Health Organization guideline
For: As, Cd, $\mathrm{Pb}$, and $\mathrm{Se}$

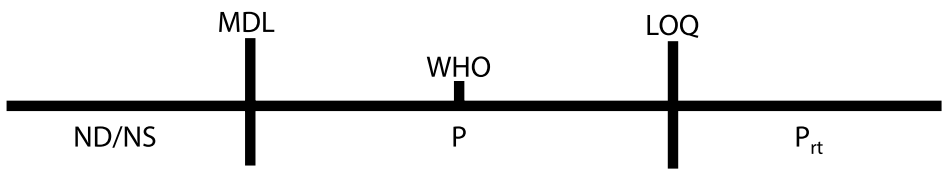

For: $\mathrm{Ba}, \mathrm{Cr}$, and $\mathrm{Cu}$
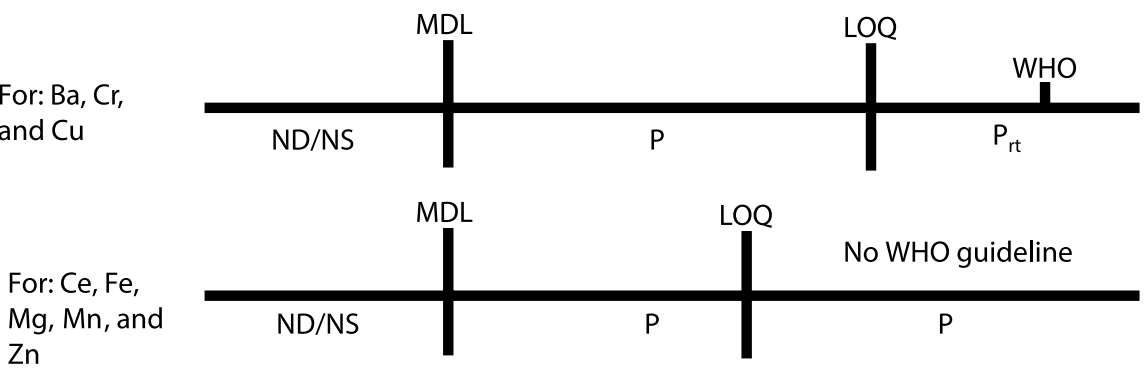
from the composition of the background control foam rinsates. $\mathrm{P}$ indicates that concentration was above the MDL but below the limit of quantification (LOQ), or above the LOQ with no WHO guideline. $\mathrm{P}_{\mathrm{rt}}$ indicates that the analyte concentration was quantifiable (> LOQ) and either below or above the WHO guidelines $(\mathrm{As}=10 \mu \mathrm{g} / \mathrm{L}, \mathrm{Ba}=1300 \mu \mathrm{g} / \mathrm{L}, \mathrm{Cd}=3 \mu \mathrm{g} / \mathrm{L}$, $\mathrm{Cr}=50 \mu \mathrm{g} / \mathrm{L}, \quad \mathrm{Cu}=2000 \mu \mathrm{g} / \mathrm{L}, \quad \mathrm{Ni}=70 \mu \mathrm{g} / \mathrm{L}$, $\mathrm{Pb}=10 \mu \mathrm{g} / \mathrm{L}, \mathrm{Sb}=20 \mu \mathrm{g} / \mathrm{L}, \mathrm{Se}=40 \mu \mathrm{g} / \mathrm{L})$ for the contaminant (WHO, 2017). It would be recommended that these water sources be retested directly for the field concentration of the dissolved analytes.

Table 2 includes a summary of the results, showing that $68 \%$ of the sites sampled contain analytes which are detectable or quantifiable $\left(\mathrm{P}\right.$ and $\left.\mathrm{P}_{\mathrm{rt}}\right)$, and $67 \%$ would be recommended for retesting $\left(\mathrm{P}_{\mathrm{rt}}\right)$. Only the analytes with a WHO guideline are listed. Fourteen percent $(14 \%)$ of the sites have more than one detectable analyte present. $\mathrm{Cu}$ and As are the only target analytes which occur above the WHO guideline, with As exceeding the guideline in $45 \%$ of the sources sampled. Other metals (with no WHO guideline) were detected in the sources, with maximum concentrations of Ce reaching approximately $3500 \mu \mathrm{g} / \mathrm{L}, \mathrm{Fe}$
$260 \mu \mathrm{g} / \mathrm{L}, \mathrm{Mg}$ 13,000 $\mu \mathrm{g} / \mathrm{L}, \mathrm{Mn} 1600 \mu \mathrm{g} / \mathrm{L}$, and Zn $94,000 \mu \mathrm{g} / \mathrm{L}$. Overall, the most commonly occurring dissolved metal found in the drinking water sources was Mn.

Figure 9 is an illustration of the total quantifiable dissolved analytes (TQDA) measured for each of the drinking water source types. TQDA is the sum of the analyte concentrations which occurred above the LOQ in the sample. These included the analytes for which a WHO guideline has been established (Table 2) plus metals such as Fe, $\mathrm{Zn}, \mathrm{Mn}$, and $\mathrm{Mg}$, for which no guideline exists. Except for two very high values near $90,000-100,000 \mu \mathrm{g} / \mathrm{L}$, the majority of the samples peaked just above $30,000 \mu \mathrm{g} / \mathrm{L}$, or $30 \mathrm{ppm}$.

Dissolved As concentration compared to source type is shown in Fig. 10. Except for one high value of approximately $285 \mu \mathrm{g} / \mathrm{L}$, maximum dissolved As concentrations of about $200 \mu \mathrm{g} / \mathrm{L}$, and concentration ranges of $45-200 \mu \mathrm{g} / \mathrm{L}$ (river), 65-179 $\mu \mathrm{g} / \mathrm{L}$ (well), and $112-178 \mu \mathrm{g} / \mathrm{L}$ (tap) were all similar. All of these values are above the WHO guideline of $10 \mu \mathrm{g} / \mathrm{L}$ and are comparable to the groundwater As concentrations (maximum $134 \mu \mathrm{g} / \mathrm{L}$ ) measured in hand tube-wells from some regions of Bangladesh
Fig. 9 Total quantifiable dissolved analytes estimated in drinking water sources. Totals represent the sum of all dissolved analytes detected at concentrations above the respective LOQs

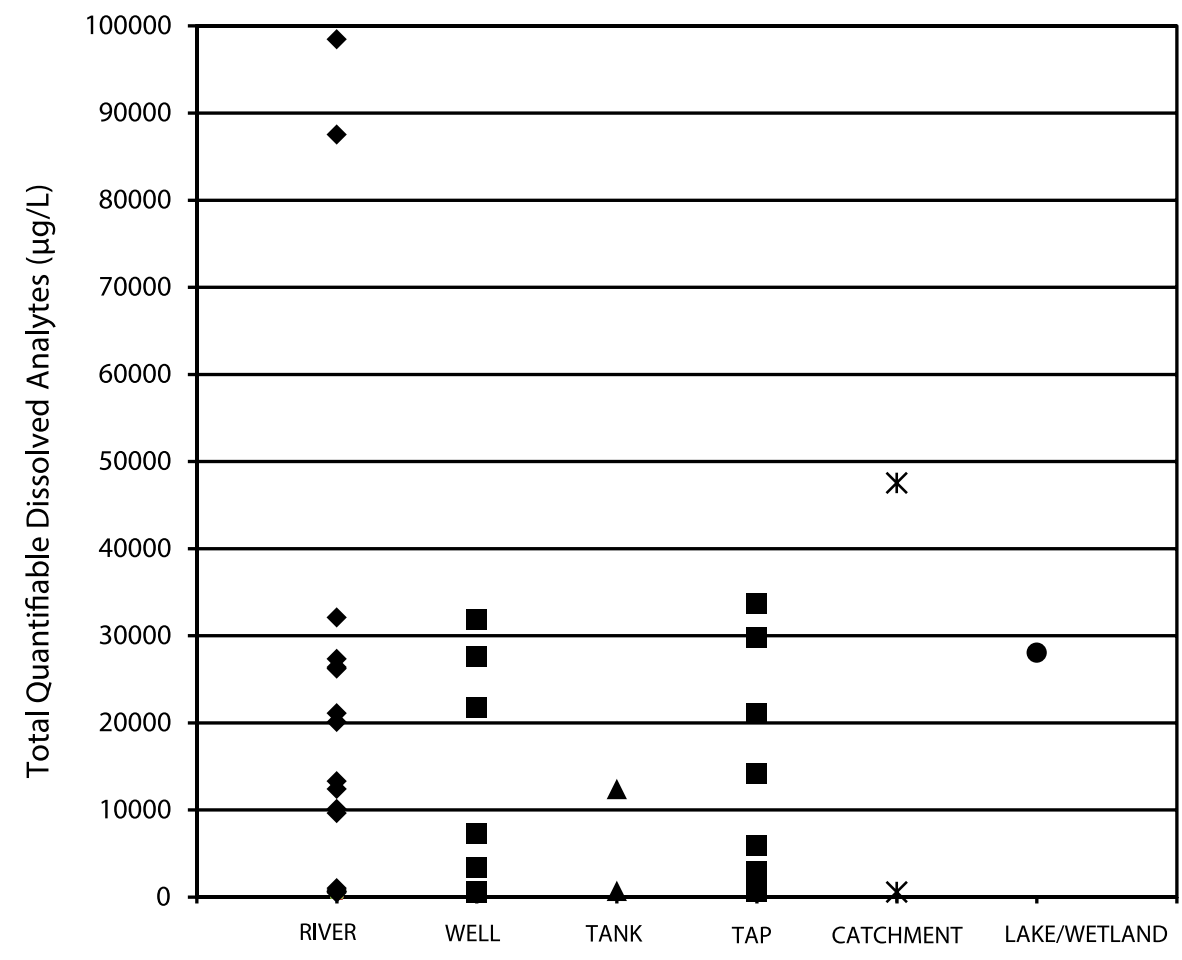

Drinking Water Source 
Fig. 10 Dissolved As concentrations estimated for the drinking water sources sampled

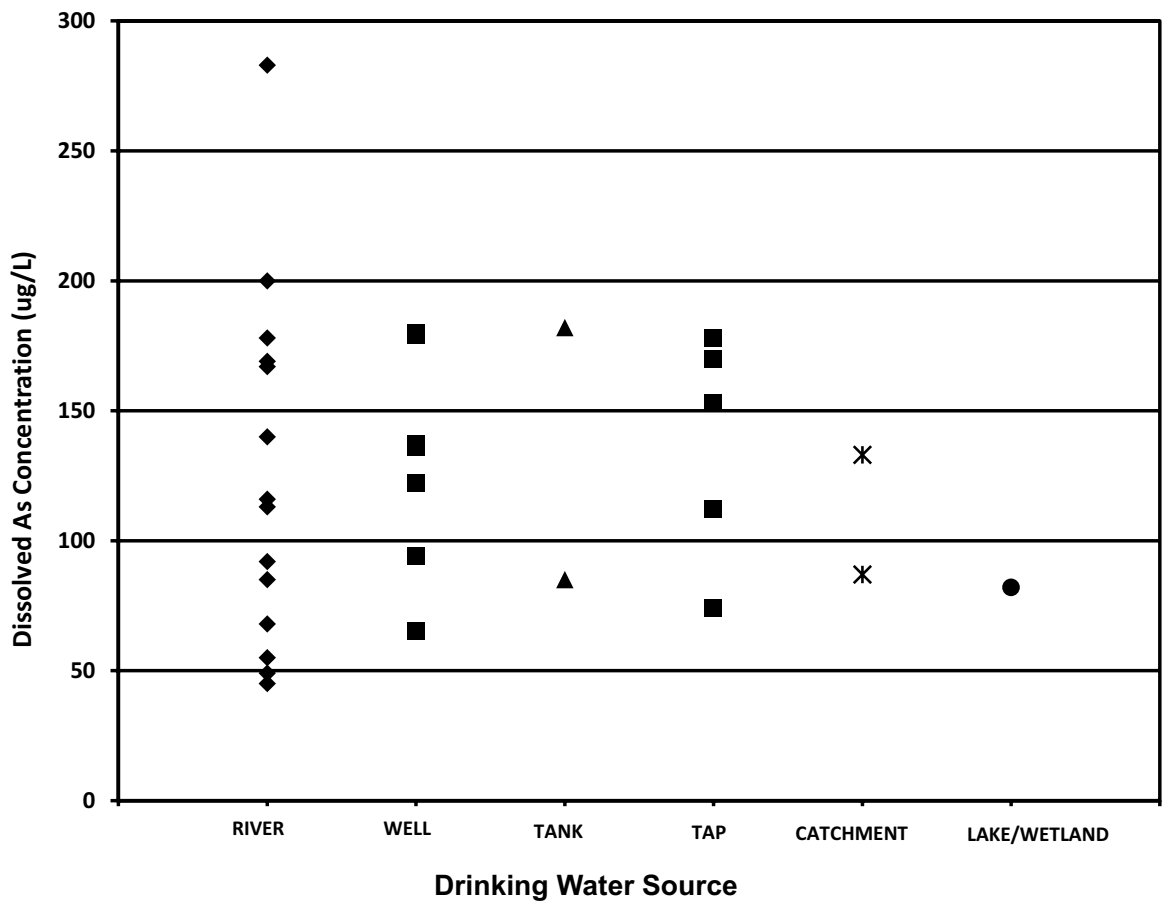

(Chakraborti et al., 2015). Other studies have reported similar orders of magnitude for As in drinking water from Croatia (Ćavar et al., 2005), Iran (Mosaferi et al., 2008), Pakistan (Baig et al., 2010), and many Latin American countries (Bundschuh et al., 2012).

No observable correlation was found between TSS and As concentrations (Fig. 11) in this study. This
Fig. 11 Dissolved As concentrations versus TSS in water sources with quantifiable As levels

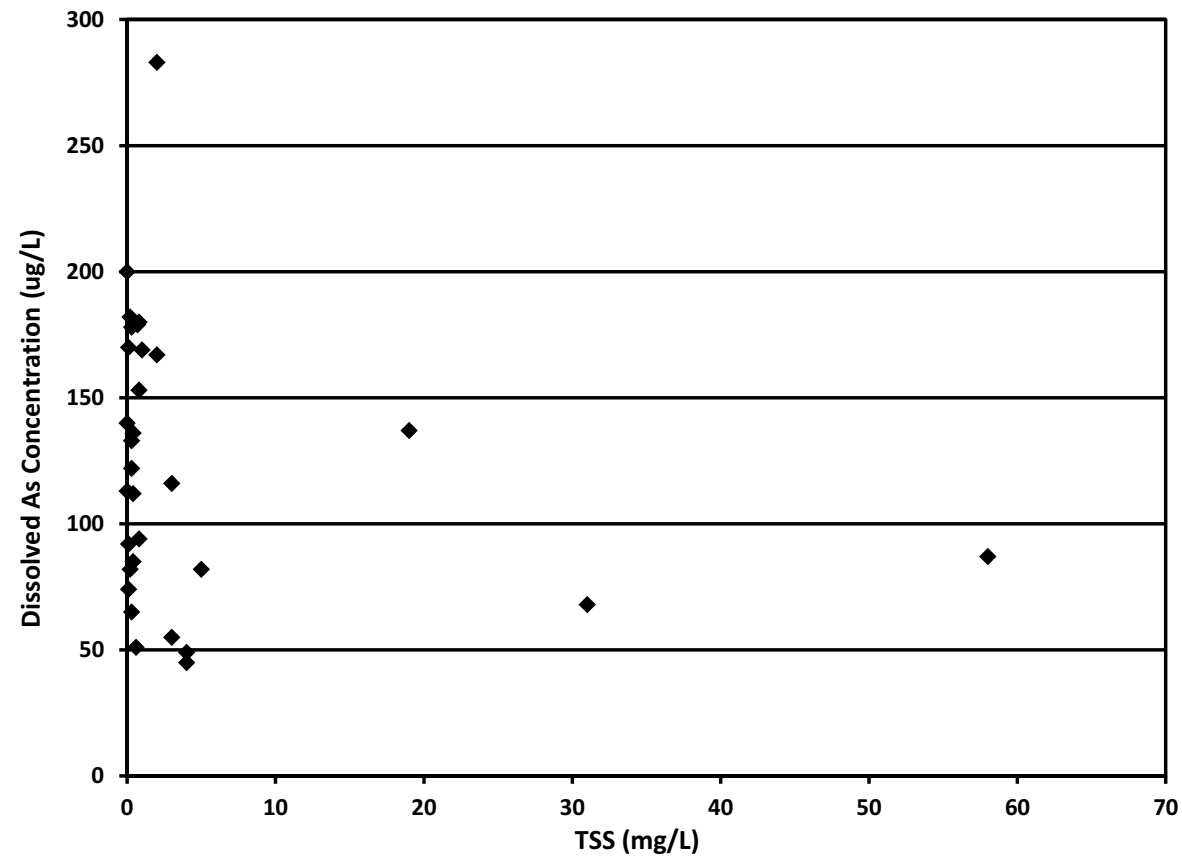


should be expected because the sources and source type vary. Nor does a correlation exist between As concentration and TSS when samples from the same source type were compared. In other studies, relationships have been observed in locations where As-bearing bedrock and As-bearing suspended particulates occur (Blake \& Peters, 2015; Cagnin et al., 2017; Nasrabaldi et al., 2018); however, the results of several studies (Baig et al., 2010; Cagnin et al., 2017; Costas et al., 2011; Grosbois et al., 2011) indicate the mineralogical composition of the suspended particulates has the largest control on dissolved As concentration, specifically controlled by redox chemistry of $\mathrm{Fe}$ and Mn oxides and oxyhydroxides. In the current study, Mn concentrations were very consistent among all samples with quantifiable As present, averaging $476 \mathrm{ppb} \pm 33 \mathrm{Mn}$. It was not possible to evaluate a relationship with $\mathrm{Fe}$ concentrations because in the majority of samples analyzed Fe concentrations were not statistically distinguishable from the $\mathrm{Fe}$ levels measured in background foam rinsates.

To the authors' knowledge, this study was the first attempt to perform a global reconnaissance survey of untreated drinking water sources using small-volume, point-of-use drinking water filters and foams, for the primary purpose of characterizing particulates and dissolved contaminants in water. Previous studies (Mull \& Hill, 2012; Smith \& Hill, 2009) have utilized dialysis filters successfully for the collection of microbes from water, and some investigations (Grytdal et al., 2018; Knappett et al., 2011) used this approach to survey a defined population who access multiple sources of drinking water, within a relatively small geographic region. The global scale and systematic protocol of the current study, from sampling through analysis, made this a potentially robust and cost-effective approach.

The field use of polyurethane foams to sample and sequester potential dissolved metal and other contaminants was useful as a reconnaissance tool by providing minimum concentration levels. Only minimum concentration levels could be estimated because of the likelihood of incomplete capture efficiency and retrieval in sampling and processing, as indicated by the results of laboratory single-element retention tests which indicate less than $100 \%$ analyte recovery from acid rinsing of spiked foams. The composition and compositional variability of the foam blocks required average background subtraction of concentrations of dissolved species which were both target analytes and constituents of the polyurethane foams. This means that copper, iron, and some other base metals may have been present at relatively high concentrations in the water sources, but were statistically indistinguishable from the concentrations in background (control) foam rinsates.

The classification of results for analyte concentrations, as presented in this paper, should be useful for disseminating reconnaissance data to stakeholders in local, regional, or national water quality decisionmaking venues. An initial indication that a water source has a metal or other contaminant present, but not above WHO guidelines, as opposed to present and above WHO guidelines will help triage sites for further investigation and remedial action. This qualitative indicator approach may be more useful than a quantitative value because any single sampling event represents only a snapshot in time-a numerical value may give a false impression of accuracy.

\section{Conclusions}

This study demonstrated that hollow-membrane pointof-use water filters and metal-capturing polyurethane foams can be used for a reconnaissance characterization of TSS and dissolved analyte concentrations in untreated drinking water. The project design of sending sampling kits to different countries to be used by trained NGO personnel, with non-technical backgrounds, for water sampling is a potentially powerful approach to accomplish a global survey. Results obtained for TSS and analyte concentrations were comparable with published results (Degueldre et al., 2000; Meybeck et al., 2003; Cavar et al., 2005; Alkhatib \& Berna, 2008; Mosaferi et al., 2008; Baig et al., 2010; Bundschuh et al., 2012; Chakraborti et al., 2015; Chowdhury et al., 2016; Cagnin et al., 2017; Nasrabadi et al., 2018; Peterson et al., 2019) reported from other locations where water was tested directly. Less than complete removal of target analytes from source waters in combination with incomplete recovery of analytes from off the foams during acid rinsing limited the reporting of analyte concentrations to minimum concentrations in the drinking water sources. A methodology of reporting analyte concentrations as present but below WHO guidelines, or quantifiably present and above WHO guidelines, with the recommendation to 
retest, may be a useful triage tool for decision-makers responsible for water-quality investigations or remediation, resulting in a more strategic allocation of resources.

Acknowledgements Many thanks to Darrel Larson and the NGO teams from Assembly of God World Missions, Assembly of God Solomon Islands, The Last Well, Amor Ministries, Mission 111, Wine to Water, Newbreak Church, Global Aim, Child Hope, Kai Alpha UCLA, WHY Limited Foundation, Give Clean Water, Stonehill Church, and Bucket Ministry for field sampling and coordination. The additional participation of Hope College students William Kleinheksel, Elizabeth Moorehead, Jacob VanderRoest, and Josiah Peterson was much appreciated.

Funding Some portions of the author's time and materials were supported by a grant from Sawyer Products, Inc. The authors also received funding support from the Hope College Biology, Chemistry, and Geology and Environmental Science Departments. Representatives of the funding organization were consulted during study design and assisted in training for the application of point-of-use filters and polyurethane foams in the field. Neither the funding organization nor its representatives performed data collection, data analysis, or interpretation of data.

Data availability The data used and analyzed which support the findings of this study are available from the corresponding author upon reasonable request.

\section{Declarations}

Conflict of interest The authors declare no competing interests.

Open Access This article is licensed under a Creative Commons Attribution 4.0 International License, which permits use, sharing, adaptation, distribution and reproduction in any medium or format, as long as you give appropriate credit to the original author(s) and the source, provide a link to the Creative Commons licence, and indicate if changes were made. The images or other third party material in this article are included in the article's Creative Commons licence, unless indicated otherwise in a credit line to the material. If material is not included in the article's Creative Commons licence and your intended use is not permitted by statutory regulation or exceeds the permitted use, you will need to obtain permission directly from the copyright holder. To view a copy of this licence, visit http://creativecommons.org/licenses/by/4.0/.

\section{References}

Alkhatib, E., \& Berna, E. (2008). Simulation of arsenic partitioning in tributaries to drinking water reservoirs. Environmental Monitoring and Assessment, 137, 197-204.
American Academy of Pediatrics Committee on Environmental Health. (2005). Lead exposure in children: Prevention, detection, and management. Pediatrics, 116(4), 1036-1046.

Aredes, S., Klein, B., \& Pawlik, M. (2012). The removal of arsenic from water using natural iron oxide minerals. Journal of Cleaner Production, 29-30, 208-213.

Badr, E. A. E., Agrama, A. A. E., \& Badr, S. A. E. (2011). Heavy metals in drinking water and human health. Egyptian Nutrition and Food Science, 41(3), 210-217.

Baig, J. A., Kazi, T. G., Shah, A. Q., Kandhro, G. A., Afridi, H. I., Arain, M. B., Jamali, M. K., \& Jalbani, N. (2010). Speciation and evaluation of Arsenic in surface water and groundwater samples: A multivariate case study. Ecotoxicology and Environmental Safety, 73, 914-923.

Bajwa, B. S., Kumar, S., Singh, S., Sahoo, S. K., \& Tripathi, R. M. (2017). Uranium and other heavy toxic elements distribution in the drinking water samples of SW-Punjab India. Journal of Radiation Research and Applied Sciences, 10, 13-19.

Blake, J. M., \& Peters, S. C. (2015). The occurrence and dominant controls on arsenic in the Newark and Gettysburg basins. Science of the Total Environment, 505, 1340-1349.

Bundschuh, J., Litter, M. I., Parvez, F., Román-Ross, G., Nicolli, H. B., Jean, J. S., Liu, C. W., López, D., Armienta, M. A., Guilherme, L. R. G., Cuevas, A. G., Cornejo, L., Cumbal, L., \& Toujaguez, R. (2012). One century of arsenic exposure in Latin America: A review of history and occurrence from 14 countries. Science of the Total Environment, 429, 2-35.

Cagnin, R. C., Quaresma, V. S., Chaillou, G., Franco, T., \& Bastos, A. C. (2017). Arsenic enrichment in sediment on the eastern continental shelf of Brazil. Science of the Total Environment, 607-608, 304-316.

Catalano, J. G., Luo, Y., \& Otemuyiwa, B. (2011). Effect of aqueous $\mathrm{Fe}$ (II) on arsenate sorption on goethite and hematite. Environmental Science \& Technology, 45, 8826-8833.

Ćavar, S., Klapec, T., Grubešić, R. J., \& Valek, M. (2005). High exposure to arsenic from drinking water at several localities in eastern Croatia. Science of the Total Environment, 339, 277-282.

Chakraborti, D., Rahman, M. M., Mukherjee, A., Alauddin, M., Hassan, M., Dutta, R. N., Pati, S., Mukherjee, S. C., Roy, S., Quamruzzman, Q., Rahman, M., Morshed, S., Islam, T., Sorif, S., Selim, M., Islam, M. R., \& Hossain, M. M. (2015). Groundwater arsenic contamination in Bangladesh-21 years of research. Journal of Trace elements in Medicine and Biology, 31, 237-248.

Chappells, H., Campbell, N., Drage, J., Fernandez, C. V., Parker, L., \& Dummer, T. J. B. (2015). Understanding the translationa of scientific knowledge about arsenic risk exposure among private well waters users in Nova Scotia. Science of the Total Environment, 505, 1259-1273.

Choubert, G., Faure-Muret, A., Chanteux, P., Roche, G., Simpson, E. S. W., Shackleton, L., Ségoufin, J., Seguin, C., \& Sougy, J. (1988). International geological map of Africa. Scale 1: 5000 000, CGMW/Unesco, Paris, 6 sheets.

Chowdhury, S., Mazumder, M. A. J., Al-Attas, O., \& Husain, T. (2016). Heavy metals in drinking water: Occurrence, 
implications, and future needs in developing countries. Science of the Total Environment, 569-570, 476-488.

Costas, M., Prego, R., Filgueiras, A. V., \& Bendicho, C. (2011). Land-ocean contributions of arsenic through a river-estuary-ria sytem (SW Europe) under the influence of arsenopyrite deposits in the fluvial basin. Science of the Total Environment, 412-413, 304-314.

Das, K. K., Das, S. N., \& Dhundasi, S. A. (2008). Nickel, its adverse health effects \& oxidative stress. Indian Journal of Medical Research, 128, 412-425.

Degueldre, C., Triay, I., Kim, J. I., Vilks, P., Laaksoharju, M., \& Miekeley, N. (2000). Groundwater colloid properties: A global approach. Applied Geochemistry, 15, 1043-1051.

De Wit, M. J., Jefery, M., Bergh, H. \& Nicolaysen, I. (1988). Geological map of sectors of Gondwana: 2 map sheets, 1:10.000.000. American Association of Petroleum Geologists.

Djukić, A., Lekić, B., Rajaković-Ognjanović, V., Veljović, D., Vulić, T., Djolić, M., Naunovic, Z., Despotović, J., \& Prodanović, D. (2016). Further insight into the mechanism of heavy metals partitioning in stormwater runoff. Journal of Environmental Management, 168, 104-110.

Dundar, M. S., \& Altundag, H. (2007). Investigation of heavy metal contaminations in the lower Sakarya river water and sediments. Environmental Monitoring and Assessment, 128, 177-181.

EPA/600/R-94/111, Method 200.7 Determination of metals and trace elements in water and wastes by inductively coupled plasma/atomic emission spectrometry, revision 4.4 in methods for the determination of metals in environmental samples-Supplement I. USEPA Office of Research and Development, May 1994.

Garzanti, E., Andó, S., France-Lanord, C., Censi, P., Vignola, P., Galy, V., \& Lupker, M. (2011). Mineralogical and chemical variability of fluvial sediments 2 . Suspendedload silt (Ganga-Brahmaputra) Bangladesh. Earth and Planetary Science Letters, 302, 107-120.

Geological Map of the world: Australia and Oceania/Geological Compilation Prepared on Behalf of the Commission for the Geological Map of the World (CGMW) by the Bureau of Mineral Resources, Geology and Geophysics, Canberra: B.M.R. for the Commission], 1965-1971.

Gowd, S. S., \& Govil, P. K. (2008). Distribution of heavy metals in surface water of Ranipet industrial area in Tamil Nadu, India. Environmental Monitoring and Assessment, 136, 197-207.

Grosbois, C., Courtin-Nomade, A., Robin, E., Bril, H., Tamura, N., Schafer, J., \& Blanc, G. (2011). Fate of arsenicbearing phases during the suspended transport in a gold mining district. Science of the Total Environment, 409, 4986-4999.

Grytdal, S. P., Weatherholtz, R., Esposito, D. H., Campbell, J., Reid, R., Gregoricus, N., Schneeberger, C., Lusk, T. S., Xiao, L., Garrett, N., Bopp, C., Hammitt, L. L., Vinje, J., Hill, V. R., O'Brien, K. L., \& Hall, A. J. (2018). Water quality, availability, and acute gastroenteritis on the Navajo nation-A pilot case-control study. Journal of Water and Health, 16(6), 1018-1028.

Hanna-Attish, M. LaChance, J., Sadler, R. C., \& Schnepp, A. C. (2016). Elevated blood lead levels in children associated with the Flint drinking water crisis: A spatial analysis of risk and public health response. American Journal of Public Health, 106, 283-290. https://doi.org/10.2105/AJPH.2015.303003

Harvey, P. J., Handley, H. K., \& Taylor, M. P. (2016). Widespread copper and lead contamination of household drinking water, New South Wales, Australia. Environmental Research, 151, 275-285.

Karagas, M. R., Gossai, A., Pierce, B., \& Ahsan, H. (2015). Drinking water arsenic contamination, skin lesions, and malignancies: A systematic review of the global evidence. Current Environmental Health Reports, 2, 52-68.

Kirkham, R. V., Chorlton, L. B., \& Carriere, J. J. (1995). Generalized geology of the world, in Generalized geological map of the world and linked databases, Open File 2915d. Geological Survey of Canada.

Knappett, P. S. K., Layton, A., McKay, L. D., Williams, D., Mailloux, B. J., Huq, M. R., Alam, M. J., Ahmed, K. M., Akita, Y., Serre, M. L., Sayler, G. S., \& van Green, A. (2011). Efficacy of hollow-fiber ultrfiltration for microbial sampling in groundwater. Ground Water, 49(1), 53-65.

Le Bot, B., Lucas, J.-P., Lacroix, F., \& Glorenne, P. (2016). Exposure of children to metals via tap water ingestion at home: Contamination and exposure data from a nationwide survey in France. Environment International, 94, 500-507.

Mamtani, R., Stern, P., Dawood, I., \& Cheema, S. (2011). Metals and disease: A global primary health care perspective. Journal of Toxicology, 2011, 1-11.

Maniquiz-Redillas, M., \& Kim, L.-H. (2014). Fractionation of heavy metals in runoff and discharge of a stormwater management system and its implications for treatment. Journal of Environmental Sciences, 26, 1214-1222.

McDowell-Boyer, L. M., Hunt, J. R., \& Sitar, N. (1986). Particle transport through porous media. Water Resources Research, 22(13), 1901-1921.

Meybeck, M., Laroche, L., Dürr, H. H., \& Syvitski, J. P. M. (2003). Global variability of daily total suspended solids and their fluxes in rivers. Global and Planetary Change, 39, 65-93.

Mohiuddin, K. M., Ogawa, Y., Zakir, H. M., Otomo, K., \& Shikazono, N. (2011). Heavy metals contamination in water and sediments of an urban river in a developing country. International Journal of Environmental Science Technology, 8(4), 723-736.

Mosaferi, M., Yunesian, M., Dastgiri, S., Mesdaghinia, A., \& Esmailnasab, N. (2008). Prevalence of skin lesions and exposure to arsenic in drinking water in Iran. Science of the Total Environment, 390, 69-76.

Muehlberger, W.R., compiler. (1992). Tectonic Map of North America: Tulsa, Okla., American Association of Petroleum Geologists, scale 1:5,000,000 (2 sheets).

Mull, B., \& Hill, V. R. (2012). Recovery of diverse microbes in high turbidity surface water samples using dead-end ultrafiltration. Journal of Microbiological Methods, 91, 429-433.

Nasrabadi, T., Ruegner, H., Schwientek, M., Bennett, J., Fazel Valipour, S., \& Grathwohl, P. (2018). Bulk metal concentrations versus total suspended solids in rivers: Timeinvariant \& catchment-specific relationships PLoS One, 13(1), 1-15, e0191314. https://doi.org/10.1371/journal. pone. 0191314 
Peterson, J.W., Stock, M.L., Brophy, E.E., \& Mattson, B.D. (2019). Using laboratory settling experiments to characterize the suspended load or moveable matrix portion of an urban aquifer: Potential relationships to land use. Journal of Environmental Engineering, 145(7), https://doi.org/10.1061/ (ASCE)EE.1943-7870.0001547

Reza, R., \& Singh, G. (2010). Heavy metal contamination and its indexing approach for river water. International Journal of Environmental Science Technology, 7(4), 785-792.

Rice, K.C., Conko, K.M., \& Hornberger, G.M. (2002). Anthropogenic sources of arsenic and copper to sediments in a suburban lake, northern Virginia. Environmental Science and Technology, 36, 4962-4967.

Sarojam, P. (2010). Analysis of wastewater for metals using ICP-OES. PerkinElmer Inc.

Smith, C. M., \& Hill, V. R. (2009). Dead-end hollow-fiber ultrfiltration for recovery of diverse microbes from water. Applied and Environmental Microbiology, 75(16), 5284-5289.

Smith, A. H., Lingas, E. O., \& Rahman, M. (2000). Contamination of drinking-water by arsenic in Bangladesh: A public health emergency. Bulletin of the World Health Organization, 78(9), 1093-1103.

WHO (World Health Organization). (2017). Guidelines for drinking-water quality. (4th ed.). Incorporating the first addendum.

WHO (World Health Organization). (2018). Fact sheet on arsenic. https://www.who.int/news-room/fact-sheets/detail/arsenic
Wonsasuluk, P., Chotpantarat, S., Siriwong, W., \& Robson, M. (2014). Heavy metal contamination and human health risk assessment in drinking water from shallow groundwater wells in an agricultural area in Ubon Ratchathani province, Thailand. Environmental Geochemistry and Health, 36, 169-182.

Wyatt, C.J., Fimbres, C., Romo, L., Mendez, R.O., \& Grijalva, M. (1998). Incidence of heavy metal contamination in water supplies in Northern Mexico. Environmental Research, A (76), 114-119.

Yang, F., Xie, S., Wei, C., Liu, J., Zhang, H., Chen, T., \& Zhang, J. (2018). Arsenic characteristics in the terrestrial environment in the vicinity of the Shimen realgar mine, China. Science of the Total Environment, 626, 77-86.

Yoshida, F., Hata, A., \& Tonegawa, H. (1999). Itai-Itai disease and the countermeasures against cadium pollution by the Kamioka mine. Environmental Economic and Policy Studies, 2, 215-229.

Zhitkovich, A. (2011). Chromium in drinking water: sources, metabolism, and cancer risks. Chemical Research in Toxicology, 24, 1617-1629.

Publisher's Note Springer Nature remains neutral with regard to jurisdictional claims in published maps and institutional affiliations. 